OPEN ACCESS

Edited by:

Tannistha Roy Barman,

Universidade de Lisboa, Portugal

Reviewed by:

Hitendra M. Patel,

Sardar Patel University, India Mohammad Bayat,

Imam Khomeini Internationa

University, Iran

*Correspondence:

Sreekantha B. Jonnalagadda jonnalagaddas@ukzn.ac.za

Specialty section:

This article was submitted to

Organic Chemistry,

a section of the journal

Frontiers in Chemistry

Received: 07 December 2020 Accepted: 10 March 2021

Published: 31 March 2021

Citation:

Kerru N, Maddila $S$ and Jonnalagadda SB (2021) A Facile and Catalyst-Free Microwave-Promoted

Multicomponent Reaction for the

Synthesis of Functionalised

1,4-Dihydropyridines With Superb

Selectivity and Yields.

Front. Chem. 9:638832.

doi: 10.3389/fchem.2021.638832

\section{A Facile and Catalyst-Free Microwave-Promoted Multicomponent Reaction for the Synthesis of Functionalised 1,4-Dihydropyridines With Superb Selectivity and Yields}

\author{
Nagaraju Kerru ${ }^{1,2}$, Suresh Maddila ${ }^{2,3}$ and Sreekantha B. Jonnalagadda ${ }^{2 *}$ \\ ${ }^{1}$ Department of Chemistry, GITAM School of Science, Gandhi Institute of Technology and Management (GITAM) University, \\ Bengaluru, India, ${ }^{2}$ School of Chemistry and Physics, University of KwaZulu-Natal, Durban, South Africa, ${ }^{3}$ Department of \\ Chemistry, GITAM Institute of Sciences, Gandhi Institute of Technology and Management (GITAM) University, Visakhapatnam, \\ India
}

We report a highly efficient green protocol for developing a novel library of 1,2,4-triazole-tagged 1,4-dihydropyridine analogs through the one-pot process from the four-component fusion of the $1 \mathrm{H}$-1,2,4-triazol-3-amine with different chosen aldehydes, diethyl acetylenedicarboxylate, and active methylene compounds in a water medium under microwave irradiation and catalyst-free conditions. Excellent yields (94-97\%) of the target products were achieved with high selectivity with a short reaction time $(<12 \mathrm{~min})$ at room temperature. The structures of the synthesized pyrimidine analogs were established by NMR and HRMS spectroscopic analysis. Simple workup, impressive yields, no column chromatography, green solvent, rapid reaction, and excellent functional group tolerance are the benefits of this protocol.

\begin{abstract}
Keywords: microwave irradiation, multi-component reaction, aqueous medium, 1,4-dihydropyridine, one-pot
\end{abstract} method

\section{INTRODUCTION}

The green chemistry approach employing non-hazardous chemicals and eco-friendly reaction conditions is most motivating in preparing broadly used and pharmacologically significant organic compounds (Kerru et al., 2019a,b). The microwave irradiation (MW) technique mostly applies environmentally benign green technology in heating to speed up the organic reactions for value-added conversions. The MW-assisted organic synthesis has become a powerful tool and an excellent non-conventional approach in the green synthetic methodologies in modern drug discovery programs (Wathey et al., 2002; Mavandadi and Pilotti, 2006). MW induces the growth of oscillation excitation and mass transference in a microwave environment, which produces vigorous heating in reaction vessels, an alternative energy source of chemical reaction for enhanced reaction rate (Polshettiwar and Varma, 2008). Furthermore, the MW technique has attracted considerable interest in organic synthesis due to the higher selectivity, improved product yield, and atom economy, which reduce the by-product generation compared to conventional thermal heating techniques (Khumalo et al., 2019). Therefore, MW-mediated organic synthesis is the preferred green method over unconventional to classical thermal processes for the rapid synthesis of a series 


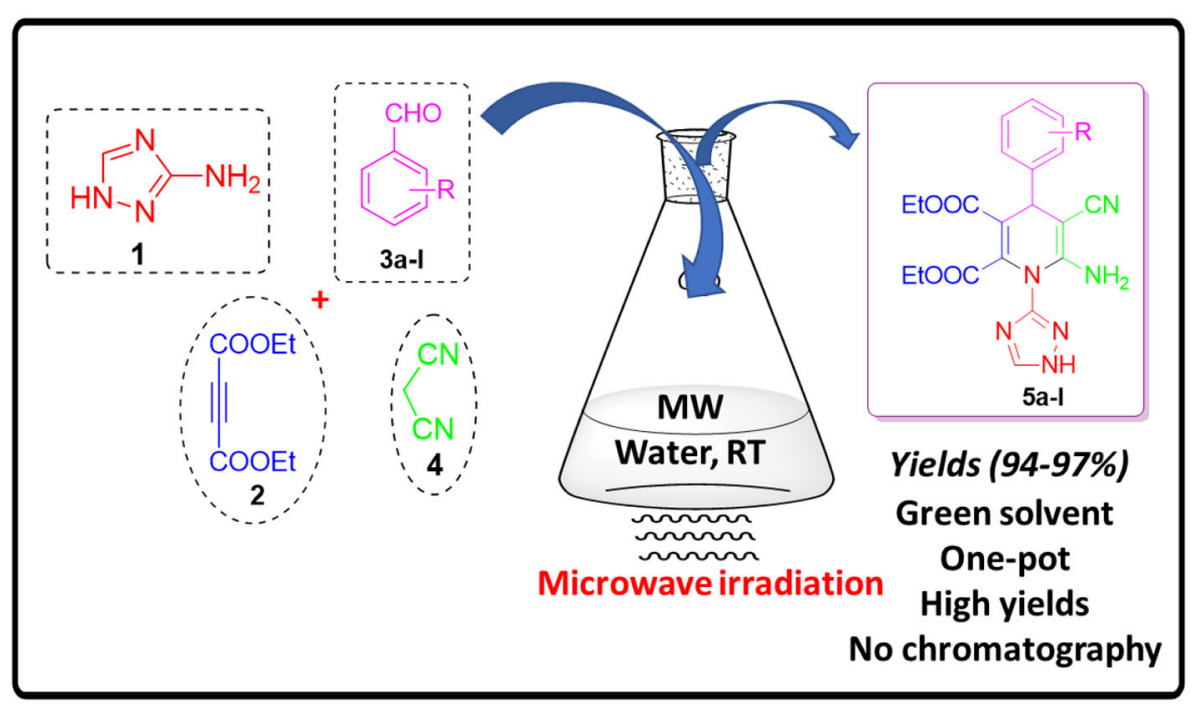

Graphical Abstract | Synthesis of Fictionalized 1,4-Dihydropyridines Under Microwave Irradiation and Aqueous Conditions.

of bioactive heterocyclic compounds (Diaz-Ortiz et al., 2019). In recent years, multicomponent reactions (MCR) have also gained eminence as ecofriendly green procedures in synthetic organic chemistry (Kerru et al., 2020a,b). The one-pot processes afford a high atom economy, high functional group tolerance, avoidance of the separation and purification methods, and minimizing the chemical waste (Kerru et al., 2020c,d). Thus, the MCR strategy is an economical approach for the synthesis of libraries of heterocyclic molecules for medicinal chemistry benefits (Maddila et al., 2020a).

Heterocyclic moieties are valuable scaffolds in the drug innovation program and exploring potential biological applications (Maddila et al., 2016; Kerru et al., 2020e). Among the $N$-heterocyclic molecules, the 1,4-dihydropyridine skeleton has gained extra significance due to a broad array of pharmacological activities such as calcium channel blocking, antidyslipidemic, antioxidant, antidiabetic, antibacterial, and antimycobacterial activities, and it has also shown to have an effect on Alzheimer's disease (Kumar et al., 2010; Sirisha et al., 2011; Niaz et al., 2015; Schaller et al., 2018; Malek et al., 2019). Recent literature reports show the increasing approval toward the synthesis of 1,4-dihydropyridine moieties through MCR strategy. Some multicomponent reactions have been reported in the literature for the synthesis of different 1,4-dihydropyridine derivatives, which employed catalysts, including sulfamic acid, $\mathrm{Fe}_{3} \mathrm{O}_{4} / \mathrm{KCC}$ 1/BPAT, Gd(OTf $)_{3}$, aminated CNTs, hydromagnesite, and nano- $\mathrm{ZrO}_{2}-\mathrm{SO}_{3} \mathrm{H}$ (Rajesh et al., 2013; Amoozadeh et al., 2016; Sadeghzadeh, 2016; Sheik Mansoor et al., 2017; Mahinpour et al., 2018; da Costa Cabrera et al., 2019). In the recent past, different procedures for 1,4-dihydropyridines in good yields have been reported to employ heterogeneous catalysts, such as $\mathrm{V}_{2} \mathrm{O}_{5} / \mathrm{ZrO}_{2}$ (Bhaskaruni et al., 2018), USY-zeolit (Alponti et al., 2021), and $\mathrm{Fe}_{3} \mathrm{O}_{4} @ \mathrm{SiO}_{2}$ (Saffarian et al.,2021). Davarpanah et al. (2019) reported nicotinic acid as a catalyst for the Hantzsch synthesis dimedone and different aldehydes under solventfree conditions obtaining the desired products in high yields. However, eco-friendly and sustainable protocols are still in demand to synthesize 1,4-dihydropyridine derivatives under green conditions.

Our continuous strive for green methodologies by applying the MCR approach, we earlier have been reported various synthetic procedures (Kerru et al., 2019c, 2020f,g,h; Maddila et al., 2020b). Herein, we describe the synthesis of 12 novel, functionalised 1,2,4-triazole-agged 1,4-dihydropyridine scaffolds through a one-pot process. A four-component reaction between 3-amino-1,2,4-triazole, diethyl acetylenedicarboxylate, malononitrile, and various chosen aldehydes in water under microwave irradiation at room temperature was utilized.

\section{EXPERIMENTAL SECTION}

\section{General Procedure for the Synthesis of 1,2,4-Triazole-1,4-Dihydropyridine (5a-I) Under Microwave}

A solution of $1 H$-1,2,4-triazol-3-amine (1, $0.1 \mathrm{mmol})$, diethyl acetylenedicarboxylate $(2,0.1 \mathrm{mmol})$, chosen aldehydes (3a-1, 0.1 $\mathrm{mmol})$, and malononitrile $(4,0.1 \mathrm{mmol})$ in water solvent $(6 \mathrm{~mL})$ were added in a $100 \mathrm{~mL}$ volume shielded combination vessel. The reaction mixture was MW aided by exploitation microwave irradiation power $(150 \mathrm{~W})$ at room temperature for $10-12 \mathrm{~min}$. The reaction progress was monitored by TLC (Hexane: Ethyl acetate; 70:30). After the completion of the reaction, the reaction mixture was transferred to the beaker. The synthesized solid product was filtered by vacuum before being the product was recrystalised with hot ethanol to offer the corresponding pure product. The structural elucidation of all the novel compounds was accomplished by different spectroscopic methods ( ${ }^{1} \mathrm{H}$ NMR, ${ }^{13} \mathrm{C}$ NMR, and HRMS). 
TABLE 1 | Optimized effect of solvent under catalyst-free for the 1,2,4-triazol-1,4-dihydropyridine (4a) formation ${ }^{\text {. }}$.

\begin{tabular}{|c|c|c|c|c|c|}
\hline \multirow[t]{2}{*}{ S.No } & \multirow[t]{2}{*}{ Medium } & \multicolumn{2}{|c|}{ Microwave } & \multicolumn{2}{|c|}{ Conventional } \\
\hline & & Time in min & Yield (\%) & Time in min & Yield $(\%)^{b}$ \\
\hline 1 & Solvent-free & 60 & 18 & 150 & 19 \\
\hline 2 & $\mathrm{CH}_{3} \mathrm{CN}$ & 60 & 36 & 120 & 24 \\
\hline 3 & DCM & 60 & 22 & 120 & 21 \\
\hline 4 & THF & 60 & 26 & 120 & 18 \\
\hline 5 & $\mathrm{AcOH}$ & 30 & 68 & 120 & 56 \\
\hline 6 & $\mathrm{H}_{2} \mathrm{O}$ & 10 & 96 & 90 & 81 \\
\hline 7 & $\mathrm{MeOH}$ & 10 & 82 & 90 & 72 \\
\hline 8 & $\mathrm{EtOH}$ & 10 & 87 & 90 & 79 \\
\hline
\end{tabular}

aThe reaction was performed with 1H-1,2,4-triazol-3-amine (1, $0.1 \mathrm{mmol})$, diethyl acetylenedicarboxylate (2, $0.1 \mathrm{~mol})$, para-methoxy benzaldehyde (3a, $0.1 \mathrm{mmol})$, malononitrile $(\mathbf{4}, 0.1 \mathrm{mmol})$ and solvent $(6.0 \mathrm{~mL})$ at room temperature.

b/solated yields.

\section{Diethyl 6-Amino-5-Cyano-4-(4- Methoxyphenyl)-1-(1H-1,2,4-Triazol-3-yl)- 1,4-Dihydropyridine-2,3-Dicarboxylate} (5a)

White solid; ${ }^{1} \mathrm{H}$ NMR $\left(400 \mathrm{MHz}, \mathrm{CDCl}_{3}\right) \delta 8.36$ (s, $1 \mathrm{H}$, triazole$\mathrm{CH}), 7.93$ (d, $J=8.9 \mathrm{~Hz}, 2 \mathrm{H}, \mathrm{Ar}-\mathrm{H}), 7.68\left(\mathrm{~s}, 2 \mathrm{H}, \mathrm{NH}_{2}\right), 7.04$ (d, $J=8.9 \mathrm{~Hz}, 2 \mathrm{H}, \mathrm{Ar}-\mathrm{H}), 6.55$ (s, 1H, NH), 4.96 (s, 1H, CH), 4.38 $\left(\mathrm{q}, J=7.6 \mathrm{~Hz}, 4 \mathrm{H}, 2 \times \mathrm{CH}_{2}\right), 3.94\left(\mathrm{~s}, 3 \mathrm{H}, \mathrm{OCH}_{3}\right), 2.34(\mathrm{t}, J=$ $\left.7.4 \mathrm{~Hz}, 6 \mathrm{H}, 2 \times \mathrm{CH}_{3}\right) ;{ }^{13} \mathrm{C} \mathrm{NMR}\left(100 \mathrm{MHz}, \mathrm{CDCl}_{3}\right) \delta 174.38$, $170.30,164.85,158.92,146.80,141.43,133.49,128.41,124.04$, $115.16,114.46,113.38,78.87,64.11,55.84,34.64,13.81$; HRMS of $\left[\mathrm{C}_{21} \mathrm{H}_{22} \mathrm{~N}_{6} \mathrm{O}_{5}+1\right]^{+}(\mathrm{m} / z) 439.1517$; Calcd: 439.1509 .

\section{RESULTS AND DISCUSSION}

To examine the solvent effect and reaction conditions for the synthesis of 1,2,4-triazole tagged 1,4-dihydropyridine $4 \mathbf{a}$ on the reaction rate and yield of the desired product and results are illustrated in Tables 1, 2. Initially, the typical reaction between the equimolar mixture of 3-amino-1,2,4-triazole (1), diethyl acetylene dicarboxylate (2), para-methoxy benzaldehyde (3a), and malononitrile (4) was performed at room temperature (RT) under solvent-free conditions. Both microwave ( $1 \mathrm{~h})$ and classical heating $(2.5 \mathrm{~h})$ reactions gave a low yield of the product (Table 1, entry 1). We further investigated the solvent's impact on the product formation by using different polar-aprotic $\left(\mathrm{CH}_{3} \mathrm{CN}\right.$, $\mathrm{DCM}$, and THF) and polar-protic $\left(\mathrm{AcOH}, \mathrm{H}_{2} \mathrm{O}, \mathrm{MeOH}\right.$, and EtOH) solvents. The polar-aprotic solvents gave the low yields of the desired product at RT under both conditions (Table 1, entries 2-4). The polar-protic solvents offered improved yields of the target product in shorter reaction time observed with both the methods (Table 1, entries 5-8). Among the solvents, water provided the best yield (96\%) with a short reaction time (10 min) under microwave irradiation conditions (Table 1, entry 6). In an aqueous medium, the hydrogen bond development with starting substrates accelerates the reaction rate.
TABLE 2 | Examined the efficiency of catalyst for the 1,2,4-triazol-1,4-dihydropyridine (4a) formation ${ }^{\mathrm{a}}$.

\begin{tabular}{|c|c|c|c|c|c|}
\hline \multirow[t]{2}{*}{ S.No } & \multirow[t]{2}{*}{ Catalyst } & \multicolumn{2}{|c|}{ Microwave } & \multicolumn{2}{|c|}{ Conventional } \\
\hline & & Time (min) & Yield $(\%)^{b}$ & Time (min) & Yield $(\%)^{b}$ \\
\hline 1 & Catalyst free & 10 & 96 & 90 & 81 \\
\hline 2 & $\mathrm{NaOH}$ & 10 & 78 & 90 & 78 \\
\hline 3 & $\mathrm{KOH}$ & 10 & 77 & 90 & 76 \\
\hline 4 & $\mathrm{Cs}_{2} \mathrm{CO}_{3}$ & 10 & 82 & 90 & 68 \\
\hline 5 & $\mathrm{~K}_{2} \mathrm{CO}_{3}$ & 10 & 73 & 90 & 79 \\
\hline 6 & $\mathrm{Et}_{3} \mathrm{~N}$ & 10 & 92 & 90 & 83 \\
\hline 7 & $\mathrm{NH}_{4} \mathrm{OAc}$ & 10 & 94 & 90 & 69 \\
\hline $\begin{array}{l}{ }^{a} \text { React } \\
\text { acetyle } \\
\text { malono } \\
{ }^{b} \text { /solate }\end{array}$ & $\begin{array}{l}\text { conditions: } \\
\text { dicarboxylate } \\
\text { rile }(\mathbf{4}, 0.1 \mathrm{mmo} \\
\text { yields. }\end{array}$ & $\begin{array}{l}1 \mathrm{H}-1,2,4-\mathrm{tri} \\
0.1 \mathrm{~mol}), p \\
\text { catalyst (10 }\end{array}$ & $\begin{array}{l}\text { ol-3-amine } \\
\text { a-methoxy b } \\
\text { \%) and wate }\end{array}$ & $\begin{array}{l}(\mathbf{1}, \quad 0.1 \\
\text { nzaldehyde } \\
(6.0 \mathrm{~mL}) \text { at }\end{array}$ & $\begin{array}{cc}\text { ol), } & \text { diethyl } \\
0.1 & \mathrm{mmol} \text {, }\end{array}$ \\
\hline
\end{tabular}

Moreover, water is eco-friendly and inexpensive than the other organic solvents. With water as the solvent, the classical heating reaction required a longer time $(1.5 \mathrm{~h})$ and gave $81 \%$ of the target product (Table 1, entry 6). The overall results revealed that the microwave irradiation protocol provided high yields of the corresponding products in less time than the classical heating. Thus, water was shown to be the best medium for product yield and reaction time for synthesizing 1,2,4-triazole-tagged 1,4-dihydropyridine scaffolds under microwave irradiation at RT.

Additionally, we investigated the catalysts' ability to enhance the yield. Runs were conducted with $\mathrm{NaOH}, \mathrm{KOH}, \mathrm{Cs}_{2} \mathrm{CO}_{3}$, $\mathrm{K}_{2} \mathrm{CO}_{3}$, trimethylamine, and ammonium acetate as a catalyst under otherwise similar conditions (Table 2). Lesser yields were detected under MW (73-94\%) for $10 \mathrm{~min}$ and under classical heating for $90 \mathrm{~min}(68-83 \%)$ (Table 2, entries 2-7) as compared to the catalyst-free condition (Table 2 , entry 1 ). The reaction without catalyst provided superior yields under both conditions.

Under these optimized conditions (water and catalyst-free), we explored the scope and efficacy of this procedure, engaging different aldehyde substrates (3a-1) and $\mathrm{C}-\mathrm{H}$ active compounds, (4) acetylenedicarboxylate (2) and reacting with 3-amino-1,2,4triazole (1) under MW conditions (Scheme 1). A total of 12 of the 1,2,4-triazole-linked 1,4-dihydropyridine analogs (5a-1) were synthesized in excellent yields (94-97\%) within a reaction time of $<12$ min (Table 3), and all were novel compounds. We observed that the different electron-deficient and electron-rich functional groups on the aldehydes' phenyl moiety were welltolerated and performed effectively, offering the desired product's excellent yields.

All the synthesized scaffold structures were elucidated and confirmed by ${ }^{1} \mathrm{H}$ and ${ }^{13} \mathrm{C}$ NMR and HRMS spectroscopic analysis (Supplementary Material). For example, the synthesized compound 5a exhibited two prominent signals at $\delta 4.96$ and $\delta 7.68 \mathrm{ppm}$ due to the $\mathrm{CH}$ and $\mathrm{NH}_{2}$ protons of the 1,4-dihydropyridine moiety. The quartet and triplet peaks appeared at $\delta 4.38$ and $\delta 2.34 \mathrm{ppm}$ attributed to the acetate $\left(\mathrm{COOCH}_{2} \mathrm{CH}_{3}\right)$ group protons. The two singlet signals at $\delta$ 6.55 and $\delta 8.36 \mathrm{ppm}$ are due to the $\mathrm{NH}$ and $\mathrm{CH}$ protons of the 


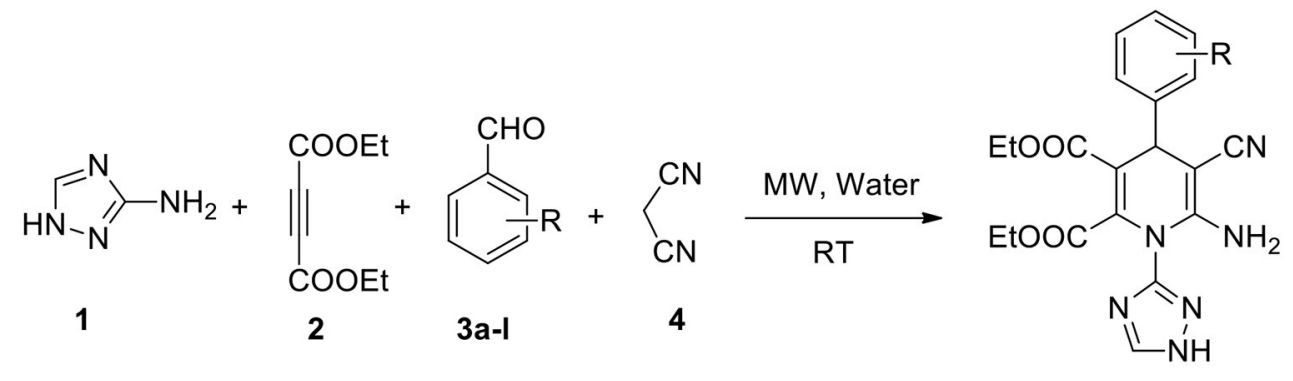

$5 a-1$

SCHEME 1 | Synthesis of 1,2,4-triazole-1,4-dihydropyridine derivatives (5a-I).

TABLE 3 | Synthesis of 1,2,4-triazole tagged 1,4-dihydropyridine scaffolds 4 a- $\mathbf{I}^{\mathrm{a}}$.

\begin{tabular}{llcccc}
\hline S.No & $\mathbf{R}$ & Compound & Time (min) & Yield (\%) & M.p./ ${ }^{\circ} \mathbf{C}$ \\
\hline 1 & $4-\mathrm{OCH}_{3}$ & $\mathbf{4 a}$ & 10 & 95 & $210-212$ \\
2 & $4-\mathrm{Cl}$ & $\mathbf{4 b}$ & 10 & 96 & $206-208$ \\
3 & $4-\mathrm{Br}$ & $\mathbf{4 c}$ & 10 & 95 & $214-216$ \\
4 & $3,4-\mathrm{di}-\mathrm{OCH}_{3}$ & $\mathbf{4 d}$ & 9 & 95 & $202-204$ \\
5 & $4-\mathrm{SCH}_{3}$ & $\mathbf{4 e}$ & 11 & 94 & $196-198$ \\
6 & $4-\mathrm{CH}_{2} \mathrm{CH}_{3}$ & $\mathbf{4 f}$ & 9 & 94 & $201-203$ \\
7 & $\left.4-\mathrm{N}_{3} \mathrm{CH}_{3}\right)_{2}$ & $\mathbf{4 g}$ & 11 & 97 & $221-223$ \\
8 & $3-\mathrm{Br}$ & $\mathbf{4 h}$ & 12 & 97 & $199-201$ \\
9 & $3-\mathrm{OCH}_{3}$ & $\mathbf{4 i}$ & 10 & 96 & $194-196$ \\
10 & $2,4,5-\mathrm{tri}-\mathrm{OCH}_{3}$ & $\mathbf{4 j}$ & 11 & 95 & $203-205$ \\
11 & $2-\mathrm{OCH}_{3}$ & $\mathbf{4 k}$ & 9 & 96 & $202-204$ \\
12 & $4-\mathrm{CH}_{3}$ & $\mathbf{4 l}$ & 12 & 97 & $209-211$ \\
\hline
\end{tabular}

aReaction conditions: 1H-1,2,4-triazol-3-amine (1, $0.1 \quad \mathrm{mmol})$, diethyl acetylenedicarboxylate (2, $0.1 \mathrm{~mol})$, para-methoxy benzaldehyde (3a-I, $0.1 \mathrm{mmol})$, malononitrile $(\mathbf{4}, 0.1 \mathrm{mmol})$, and water $(6.0 \mathrm{~mL})$ under microwave irradiation at $R T$.

${ }^{\mathrm{b}}$ Isolated yields.

1,2,4-triazole ring moiety. Another singlet was appeared at $\delta$ $3.94 \mathrm{ppm}$ belongs to the three protons of the methoxy group $\left(\mathrm{OCH}_{3}\right)$ on the phenyl ring. The other residual phenyl ring protons appeared at their corresponding aromatic positions in the ${ }^{1} \mathrm{H}$ NMR spectrum. The acetate moiety's carbonyl carbon exhibited at $\delta 174.38$ and $170.30 \mathrm{ppm}$ in the ${ }^{13} \mathrm{C}$ NMR spectrum. The HRMS spectrum further confirmed the formation of the condensation product $5 \mathrm{a}$ with the molecular-ion peak $(\mathrm{M}+\mathrm{H})$ at $\mathrm{m} / z$ 439.1517. All the synthesized derivatives were established as the 1,2,4-triazole-linked 1,4-dihydropyridine analogs based on the structural characterization data.

Table 4 illustrates the comparison of the results from the proposed green method and literature reported protocols in terms of experimental conditions, reaction time, and yield. An observation of the table's data indicates that eco-friendly solvent water provides superior results under microwave irradiation at $\mathrm{RT}$ in all respects compared to the reported methods. Thus, the MW method offers higher yields, excellent selectivity, simple workup, and a rapid reaction under catalyst-free green solvent conditions.

A probable mechanism to synthesize 1,2,4-triazole-linked 1,4-dihydropyridine analogs through a one-pot process is
TABLE 4 | Comparison of the current reported procedure with previously described methods for the synthesis of 1,4-dihydropyridines.

\begin{tabular}{|c|c|c|c|c|}
\hline S.No & Catalyst & $\begin{array}{l}\text { Reaction } \\
\text { conditions }\end{array}$ & $\begin{array}{l}\text { Time } \\
\text { (h) }\end{array}$ & Yield(\%) ${ }^{\text {Ref }}$ \\
\hline 1 & Sulfamic acid & Reflux/MeOH & 24 & 47-92 (da Costa Cabrera et al., 2019) \\
\hline 2 & $\begin{array}{l}\mathrm{Fe}_{3} \mathrm{O}_{4} / \mathrm{KCC}- \\
\text { 1/BPAT }\end{array}$ & Reflux/Water & 4 & 79-88 (Sadeghzadeh, 2016) \\
\hline 3 & $\mathrm{Gd}(\mathrm{OTf})_{3}$ & RT/Ethanol & 6 & 82-89 (Sheik Mansoor et al., 2017) \\
\hline 4 & $\begin{array}{l}\text { Aminated } \\
\text { CNTs }\end{array}$ & Reflux/ethanol & 6 & 80-96 (Mahinpour et al., 2018) \\
\hline 5 & Hydromagnesite & $90^{\circ} \mathrm{C} /$ Water & 0.75 & 80-98 (Rajesh et al., 2013) \\
\hline 6 & $\begin{array}{l}\mathrm{Nano}-\mathrm{ZrO}_{2-}^{-} \\
\mathrm{SO}_{3} \mathrm{H}\end{array}$ & $\begin{array}{l}80^{\circ} \mathrm{C} / \text { solvent- } \\
\text { free }\end{array}$ & -1 & 84-93 (Amoozadeh et al., 2016) \\
\hline 7 & Catalyst-free & $\begin{array}{l}\text { Microwave/ < } \\
\text { RT/Water }\end{array}$ & $<12 \min$ & 94-97 (This work) \\
\hline
\end{tabular}

proposed (Scheme 2). Water plays a significant part in this conversion. The electrophilicity of the aldehyde substrate (3a-1) carbonyl carbon enhances through the hydrogen bond between the water and carbonyl group (Ramesh and Lalitha, 2016; Kerru et al., 2020i). Simultaneously, the acidic hydrogen of malononitrile (4) hydrogen bonds with the oxygen of the $\mathrm{H}_{2} \mathrm{O}$ molecule. Then, the Knoevenagel condensation product (I) forms by the elimination of water molecules. Subsequently, 1,2,4triazole-amine (1) reacts with diethyl acetylenedicarboxylate (2), resulting in the formation of the enolate intermediate (II). Then, through the Michael addition, the intermediate (I) reacts with intermediate (II), generating the transient intermediate (III) (Maddila et al., 2019). The intermediate (III) undergoes intramolecular cyclisation (IV) followed by tautomerisation, finally leading to the generation of the target compound, 1,2,4triazole-linked 1,4-dihydropyridine derivative (5a-1).

\section{CONCLUSION}

We described the procedure for synthesizing 12 novel biologically imperative 1,2,4-triazole-tagged 1,4-dihydropyridine analogs with excellent yields (94-97\%) under microwave irradiation conditions. The one-pot reaction between the 3-amino-1,2,4-triazole, diethyl acetylenedicarboxylate, malononitrile, and various selected aldehydes was effectively 


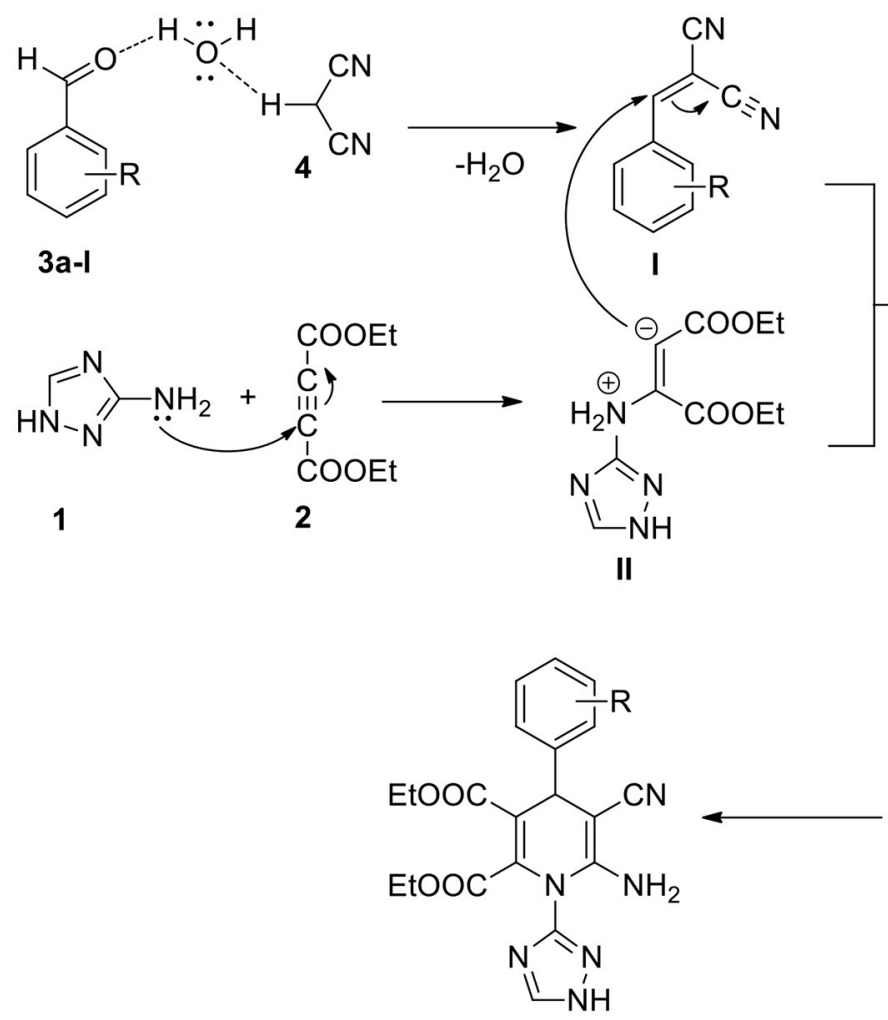

5a-I

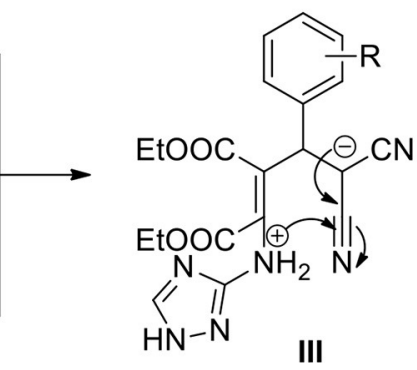<smiles>[R]OC(=O)C1=C(C(=O)OCC)N(c2nc[nH]n2)C(=N)[C@@](C#N)(CC)[C@H]1c1ccc(C)cc1</smiles>

IV

SCHEME 2 | The possible mechanism for the synthesis of 1,2,4-triazole-1,4-dihydropyridines.

accomplished in a water medium at $\mathrm{RT}$ in $<12$ min reaction time. The structural elucidation of the synthesized derivatives was achieved by HRMS, ${ }^{1} \mathrm{H}$, and ${ }^{13} \mathrm{C}$ NMR spectral analysis. The method's various benefits are catalyst-free and show swift reactions, high selectivity, excellent yields, green solvents, and avoidance of column chromatography and hazardous reagents.

\section{DATA AVAILABILITY STATEMENT}

The original contributions presented in the study are included in the article/Supplementary Material, further inquiries can be directed to the corresponding author.

\section{AUTHOR CONTRIBUTIONS}

NK performed experimental studies and wrote the original draft. SM performed validation and spectral

\section{REFERENCES}

Alponti, L. H. R., Picinini, M., Urquieta-Gonzalez, E. A., and Correa, A. G. (2021). USY-zeolite catalysed synthesis of 1,4-dihydropyridines under microwave irradiation: structure and recycling of the characterization of synthesized molecules. SJ designed project planning, proofreading, and editing. All authors contributed to the article and approved the submitted version.

\section{FUNDING}

The authors are very grateful to the University of KwaZulu Natal, Durban, South Africa, and GITAM Deemed to be University, Bengaluru and Visakhapatnam, India, for financial and research support.

\section{SUPPLEMENTARY MATERIAL}

The Supplementary Material for this article can be found online at: https://www.frontiersin.org/articles/10.3389/fchem. 2021.638832/full\#supplementary-material

catalyst. J. Mol. Struct. 1227:129430. doi: 10.1016/j.molstruc.2020 129430

Amoozadeh, A., Rahmani, S., Bitaraf, M., Abadi, F. B., and Tabrizian, E. (2016). Nano-zirconia as an excellent nano support for immobilisation of sulfonic acid: a new, efficient and highly recyclable heterogeneous solid 
acid nanocatalyst for multicomponent reactions. New J. Chem. 40, 770-780. doi: $10.1039 / \mathrm{C} 5 \mathrm{NJ} 02430 \mathrm{G}$

Bhaskaruni, S. V. H. S., Maddila, S., Evan Zyl, W., and Jonnalagadda, S. B. (2018). $\mathrm{V}_{2} \mathrm{O}_{5} / \mathrm{ZrO}_{2}$ as an efficient reusable catalyst for the facile, green, one-pot synthesis of novel functionalised 1,4-dihydropyridine derivatives. Catal. Today 309, 276-281. doi: 10.1016/j.cattod.2017. 05.038

da Costa Cabrera, D., Santa-Helena, E., Leal, H. P., de Moura, R. R., Nery, L. E. M., Gonçalves, C. A. N., et al. (2019). Synthesis and antioxidant activity of new lipophilic dihydropyridines. Bioorg. Chem. 84, 1-16. doi: 10.1016/j.bioorg.2018.11.009

Davarpanah, J., Ghahremani, M., and Najafi, O. (2019). Synthesis of 1,4dihydropyridine and polyhydroquinoline derivatives via Hantzsch reaction using nicotinic acid as a green and reusable catalyst. J. Mol. Struct. 1177, 525-535. doi: 10.1016/j.molstruc.2018.10.002

Diaz-Ortiz, A., Prieto, P., and delaHo, A. (2019). A critical overview on the effect of microwave irradiation in organic synthesis. Chem. Rec. 19, 85-97. doi: $10.1002 /$ tcr.201800059

Kerru, N., Bhaskaruni, S. V. H. S., Gummidi, L., Maddila, S. N., Maddila, S., and Jonnalagadda, S. B. (2019b). Recent advances in heterogeneous catalysts for the synthesis of imidazole derivatives. Synth. Commun. 49, 2437-2459. doi: 10.1080/00397911.2019.1639755

Kerru, N., Bhaskaruni, S. V. H. S., Gummidi, L., Maddila, S. N., Singh, P., and Jonnalagadda, S. B. (2020c). Efficient synthesis of novel pyrazole linked 1,2,4-triazolidine-3-thiones using bismuth on zirconium oxide as a recyclable catalyst in aqueous medium. Mol. Divers. 24, 345-354. doi: 10.1007/s11030-019-09957-0

Kerru, N., Gummidi, L., Bhaskaruni, S. V. H. S., Maddila, S. N., and Jonnalagadda, S. B. (2020i). Green synthesis and characterisation of novel 1,2,4,5-tetrasubstituted imidazole derivatives with eco-friendly red brick clay as efficacious catalyst. Mol. Divers. 24, 889-901. doi: 10.1007/s11030-01910000-5

Kerru, N., Gummidi, L., Gangu, K. K., Maddila, S., and Jonnalagadda, S. B. (2020d). Synthesis of novel furo[3,2-c]coumarin derivatives through multicomponent $[4+1]$ cycloaddition reaction using $\mathrm{ZnO} / \mathrm{FAp}$ as a sustainable catalyst. ChemistrySelect 5, 4104-4110. doi: 10.1002/slct.202 000796

Kerru, N., Gummidi, L., Maddila, S., Gangu, K. K., and Jonnalagadda, S. B. $(2020 \mathrm{e})$. A review on recent advantages in nitrogen-containing molecules and their biological applications. Molecules 25:1909. doi: 10.3390/molecules250 81909

Kerru, N., Gummidi, L., Maddila, S., and Jonnalagadda, S. B. (2020h). Gadolinium oxide loaded zirconia and multicomponent synthesis of novel dihydropyrazolo[3,4-d]pyridines under green conditions. Sustain. Chem. Pharm. 18:100316. doi: 10.1016/j.scp.2020.100316

Kerru, N., Gummidi, L., Maddila, S. N., Bhaskaruni, S. V. H. S., and Jonnalagadda, S. B. (2020a). $\mathrm{Bi}_{2} \mathrm{O}_{3} / \mathrm{FAp}$, a sustainable catalyst for synthesis of dihydro-[1,2,4]triazolo[1,5-a]pyrimidine derivatives through green strategy. Appl. Organomet. Chem. 34:e5590. doi: 10.1002/a oc. 5590

Kerru, N., Gummidi, L., Maddila, S. N., Bhaskaruni, S. V. H. S., and Jonnalagadda, S. B. (2020f). $\mathrm{V}_{2} \mathrm{O}_{5} / \mathrm{FAp}$, a sustainable catalyst for the synthesis of novel $[1,3,4]$ thiadiazolo-[3,2-a]pyrimidines via green strategy with excellent yields and atom economy. RSC Adv. 10, 19803-19810. doi: 10.1039/D0RA $02298 \mathrm{E}$

Kerru, N., Gummidi, L., Maddila, S. N., Bhaskaruni, S. V. H. S., and Jonnalagadda, S. B. (2020g). One-pot green synthesis of novel 5,10-dihydro$1 \mathrm{H}$-pyrazolo[1,2-b]phthalazine derivatives with eco-friendly biodegradable eggshell powder as efficacious catalyst. Res. Chem. Intermed. 46, 3067-3068. doi: 10.1007/s11164-020-04135-6

Kerru, N., Gummidi, L., Maddila, S. N., Gangu, K. K., and Jonnalagadda, S. B. (2020b). Four-component rapid protocol with nickel oxide loaded on fluorapatite as a sustainable catalyst for the synthesis of novel imidazole analogs. Inorg. Chem. Commun. 116:107935. doi: 10.1016/j.inoche.2020. 107935

Kerru, N., Maddila, S., and Jonnalagadda, S. B. (2019a). Design of carbon-carbon and carbon-heteroatom bond formation reactions under green conditions. Curr. Org. Chem. 23, 3156-3192. doi: 10.2174/1385272823666191202105820
Kerru, N., Maddila, S. N., Maddila, S., Sobhanapuram, S., and Jonnalagadda, S. B. (2019c). Synthesis and antimicrobial activity of novel thienopyrimidine linked rhodanine derivatives. Can. J. Chem. 97, 94-99. doi: 10.1139/cjc-20 $18-0220$

Khumalo, M. R., Maddila, S. N., Maddila, S., and Jonnalagadda, S. B. (2019). A multicomponent, facile and catalyst-free microwave-assisted protocol for the synthesis of pyrazolo-[3,4-b]-quinolines under green conditions. RSC Adv. 9, 30768-30772. doi: 10.1039/C9RA04604F

Kumar, A., Maurya, R. A., Sharma, S., Kumar, M., and Bhatia, G. (2010). Synthesis and biological evaluation of $\mathrm{N}$-aryl-1,4-dihydropyridines as novel antidyslipidemic and antioxidant agents. Eur. J. Med. Chem. 45, 501-509. doi: 10.1016/j.ejmech.2009.10.036

Maddila, S., Gorle, S., Seshadri, N., Lavanya, P., and Jonnalagadda, S. B. (2016). Synthesis, antibacterial and antifungal activity of novel benzothiazole pyrimidine derivatives. Arab. J. Chem. 9, 681-687. doi: 10.1016/j.arabjc.2013.04.003

Maddila, S., Kerru, N., Chinnam, S., and Jonnalagadda, S. B. (2019). Microwaveassisted multicomponent reaction: a green and catalyst-free method for the synthesis of poly-functionalised 1,4-dihydropyridines. ChemistrySelect 4, 9451-9454. doi: 10.1002/slct.201902779

Maddila, S., Kerru, N., and Jonnalagadda, S. B. (2020b). Synthesis and antimicrobial evaluation of novel pyrano[2,3-d]-pyrimidine bearing 1,2,3-triazoles. Chem. Data Coll. 28:100486. doi: 10.1016/j.cdc.2020. 100486

Maddila, S. N., Maddila, S., Kerru, N., Bhaskaruni, S. V. H. S., and Jonnalagadda, S. B. (2020a). Facile one-pot synthesis of arylsulfonyl- $4 H$-pyrans catalysed by Ru loaded fluorapatite. ChemistrySelect 5, 1786-1791. doi: 10.1002/slct.2019 01867

Mahinpour, R., Moradi, L., Zahraei, Z., and Pahlevanzadeh, N. (2018). New synthetic method for the synthesis of 1,4-dihydropyridine using aminated multiwalled carbon nanotubes as high efficient catalyst and investigation of their antimicrobial properties. J. Saudi Chem. Soc. 22, 876-885. doi: 10.1016/j.jscs.2017.11.001

Malek, R., Maj, M., Wnorowski, A., Jozwiak, K., Martin, H., Iriepa, I., et al. (2019). Multi-target 1,4-dihydropyridines showing calcium channel blockade and antioxidant capacity for Alzheimer's disease therapy. Bioorg. Chem. 91:103205. doi: 10.1016/j.bioorg.2019.103205

Mavandadi, F., and Pilotti, A. (2006). The impact of microwave-assisted organic synthesis in drug discovery. Drug Discov. Today 11, 165-174. doi: 10.1016/S1359-6446(05)03695-0

Niaz, H., Kashtoh, H., Khan, J. A. J., Khan, A., tul-Wahab, A., Alam, M. T., et al. (2015). Synthesis of diethyl 4-substituted-2,6-dimethyl-1,4dihydropyridine-3,5-dicarboxylates as a new series of inhibitors against yeast $\alpha$-glucosidase. Eur. J. Med. Chem. 95,199-209. doi: 10.1016/j.ejmech.2015. 03.018

Polshettiwar, V., and Varma, R. S. (2008). Aqueous microwave chemistry: a clean and green synthetic tool for rapid drug discovery. Chem. Soc. Rev. 37, 1546-1557. doi: 10.1039/b716534j

Rajesh, U. C., Manohar, S., and Rawat, D. S. (2013). Hydromagnesite as an efficient recyclable heterogeneous solid base catalyst for the synthesis of flavanones, flavonols and 1,4-dihydropyridines in water. Adv. Synth. Catal. 355, 3170-3178. doi: $10.1002 /$ adsc. 201300555

Ramesh, R., and Lalitha, A. (2016). Facile and green chemistry access to 5-aryl1,2,4-triazolidine-3-thiones in aqueous medium. ChemistrySelect 1, 2085-2089. doi: $10.1002 /$ slct. 201600348

Sadeghzadeh, S. M. (2016). Bis(4-pyridylamino) triazine-stabilised magnetite KCC-1: a chemoselective, efficient, green and reusable nanocatalyst for the synthesis of N-substituted 1,4-dihydropyridines. RSC Adv. 6, 99586-99594. doi: 10.1039/C6RA20488K

Saffarian, H., Karimi, F., Yarie, M., and Zolfigo, M. A. (2021). $\mathrm{Fe}_{3} \mathrm{O}_{4} @ \mathrm{SiO}_{2} @\left(\mathrm{CH}_{2}\right)_{3}$-urea-quinoline sulfonic acid chloride: a novel catalyst for the synthesis of coumarin containing 1,4 dihydropyridines. J. Mol. Struct. 1224:129294. doi: 10.1016/j.molstruc.2020.129294

Schaller, D., Gunduz, M. G., Zhang, F. X., Zamponi, G. W., and Wolber, G. (2018). Binding mechanism investigations guiding the synthesis of novel condensed 1,4-dihydropyridine derivatives with L-/T-type calcium channel blocking activity. Eur. J. Med. Chem. 155, 1-12. doi: 10.1016/j.ejmech.2018. 05.032 
Sheik Mansoor, S., Aswin, K., Logaiya, K., and Sudhan, S. P. N. (2017). An efficient one-pot multi component synthesis of polyhydroquinolin derivatives through hantzsch reaction catalysed by gadolinium. Triflate. Arab. J. Chem. 10, S546-S553. doi: 10.1016/j.arabjc.2012.10.017

Sirisha, K., Bikshapathi, D., Achaiah, G., and Reddy, V. M. (2011). Synthesis, antibacterial and antimycobacterial activities of some new 4 -aryl/heteroaryl2,6-dimethyl-3,5-bis-N-(aryl)-carbamoyl-1,4-dihydropyridines. Eur. J. Med. Chem. 46, 1564-1571. doi: 10.1016/j.ejmech.2011.02.003

Wathey, B., Tierney, J., Lidstrom, P., and Westman, J. (2002). The impact of microwave-assisted organic chemistry on drug discovery. Drug Discov. Today 7, 373-380. doi: 10.1016/S1359-6446(02)02178-5
Conflict of Interest: The authors declare that the research was conducted in the absence of any commercial or financial relationships that could be construed as a potential conflict of interest.

Copyright (c) 2021 Kerru, Maddila and Jonnalagadda. This is an open-access article distributed under the terms of the Creative Commons Attribution License (CC BY). The use, distribution or reproduction in other forums is permitted, provided the original author(s) and the copyright owner(s) are credited and that the original publication in this journal is cited, in accordance with accepted academic practice. No use, distribution or reproduction is permitted which does not comply with these terms. 